\title{
Los bienes culturales intangibles que se han desarrollado en un contexto regional
}

\author{
Intangible cultural goods that have \\ developed in a regional context \\ Dra. Marcela Molina \\ Académica de la Universidad Católica Argentina, sede Mendoza, Argentina \\ $\checkmark$ marcelasandramolina@uca.edu.ar [orcid.org/0000-0003-3902-4619]
}

\begin{abstract}
RESUMEN
En este artículo analizaremos el marco legal aplicable a los bienes culturales intangibles que se han desarrollado en un contexto regional y, por tanto, están sujetos a ordenamientos jurídicos de Estados limítrofes. A los fines propuestos, relevamos las normas argentinas vigentes y declaratorias para demostrar la complejidad del sistema jurídico argentino sobre patrimonio cultural; también, para identificar vacíos normativos, remisiones erróneas y examinar la suficiencia o no de los medios de protección frente al uso indebido y prácticas que pueden vulnerar su autenticidad. En una segunda instancia, relevamos la normativa uruguaya sobre patrimonio cultural y las principales acciones estatales para su preservación. Finalmente, abordamos los casos del "Tango" (involucra la cultura uruguaya y argentina) y la "Payada" (originaria de Argentina, Uruguay, Paraguay y zona sur de Brasil), indagando sobre potenciales conflictos jurídicos y las vías pacíficas de solución.
\end{abstract}

PALABRAS CLAVE: patrimonio cultural intangible, salvaguarda.

\begin{abstract}
In this article, the author analyzes the intangible cultural heritage legislation that has been developed in a regional context; that is why, they are subject to laws of bordering states. For these purposes, she studies on Argentine laws and she identifies regulatory gaps, mistakes and she examines the sufficiency or not of the means of protection against misuse and practices that may violate their authenticity. Secondly, she reviews the Uruguayan legislation on cultural heritage and the main state actions for its preservation. Finally, she


analyzes the cases of "Tango" (that involves Uruguayan and Argentine culture) and "Payada" (that has origined from Argentina, Uruguay, Paraguay and southern Brazil), and she researchs potential legal conflicts and peaceful ways to solve them.

KEY WORDS: intangible cultural heritage, safeguarding.

\section{INTRODUCCIÓN}

En los últimos años, en la República Argentina se han declarado numerosos bienes tangibles e intangibles como patrimonio cultural nacional, provincial y municipal. También, se han encarado gestiones patrimoniales en los distintos niveles de gobierno con distinto alcance e impacto.

Algunos objetos intangibles se han desarrollado en un contexto regional por lo que han sido declarados como patrimonio cultural por dos o más países limítrofes. Entre ellos, el “Tango” como bien cultural y que involucra la cultura uruguaya y argentina; asimismo, el sistema cultural de la yerba mate -Ka'a” como manifestación cultural argentina y paraguaya (comprende la planta, el ritual y/o práctica de "tomar mate” y la bebida); la "Payada” originaria de la Argentina, Uruguay, Paraguay, el sureste de Brasil; incluso, mencionada como manifestación cultural de Chile (denominada "paya”); también el "Chamamé” originario de Corrientes-Argentina y amplia difusión en Paraguay y sur de Brasil (Río Grande del Sur y Mato Grosso¹).

El Tango ha sido incorporado a la Lista del Patrimonio Cultural Inmaterial de la Humanidad como originario de Argentina y Uruguay (2009) mediante Decisión 4.COM 13.01² de la UNESCO. La Payada fue incorporada a la Lista del MERCOSUR en el año 201533; poco después se incorporaron a esa lista comunitaria, el "Chamamé” (2017) y el sistema cultural de la yerba mate -Ka'a” (20185).

Estas manifestaciones intangibles se desarrollaron en el seno de grupos humanos que formaron parte del ex-Virreinato del Río de la Plata, y posteriormente, al conformar Estados independientes (Argentina, Uruguay, Paraguay y sur de Brasil), pasaron a estar regidas por ordenamientos jurídicos distintos.

Estos bienes culturales regionales exigen medidas coordinadas de todos los Estados involucrados en pos de su catalogación, defensa de su autenticidad y tipicidad, sensibilización, difusión y promoción; pero además, las normas jurídicas deben prever soluciones a numerosos

1 Estado de Mato Grosso do Sul, Lei Estadual N 3.837 (sancionada el 23/12/2009, publicada en Diário Oficial do Estado do Mato Grosso do Sul del 28/12/2009) y la Lei EWstadual N4.113/201 (sancionada el 17/11/2011, publicada en Diário Oficial do Estado do Mato Grosso do Sul del 18/11/2011), que establece que Rio Brilhante es la ciudad capital del chamamé.

2 Intergovernmental Committee for the Safeguarding of the Intangible Cultural Heritage, Fourth session Abu Dhabi, United Arab Emirates, 28 september to 2 October 2009. [Disponible en: https://ich.unesco.org/doc/src/ ITH-09-4.COM-CONF.209-13-Rev.2-EN.pdf] (consultado 28/11/2018.

$3 \quad 38^{a}$ Reunión de Ministros de Cultura de la región, celebrada el 18 de junio de 2015 en Brasilia, Brasil.

$4 \quad 14^{\text {a }}$ Reunión de Comisión de Patrimonio Cultural del Mercosur (CPC) del 30 y 31 de mayo de 2017, Ciudad de Buenos Aires, Acta No 1 /17 MERCOSUR/RMC/CPC.

$5 \quad 44^{\mathrm{a}}$ Reunión de Ministros de Cultura celebrada el 16 de noviembre de 2018 en la ciudad de Montevideo, Uruguay. 
conflictos jurídicos que se pueden presentar en torno de éstos.

En este artículo estudiamos las normas jurídicas sancionadas en los Estados limítrofes (especialmente el derecho argentino) con respecto a dos bienes culturales intangibles: el “Tango" (Patrimonio Cultural Inmaterial de la Humanidad) y la "Payada" (Patrimonio Cultural del MERCOSUR). Estas manifestaciones culturales presentan un matiz peculiar por cuanto han sido identificadas y catalogadas por Estados miembros del MERCOSUR (Argentina y Uruguay). En consecuencia, están sujetas a normas comunitarias.

A los fines propuestos, relevamos las normas argentinas vigentes (nacionales, provinciales y algunas normas municipales) para demostrar la complejidad del sistema jurídico argentino sobre patrimonio cultural en el marco del deslinde de competencia constitucional; también, para identificar vacíos normativos, remisiones erróneas y examinar la suficiencia o no de los medios de protección frente al uso indebido y prácticas que pueden vulnerar su autenticidad.

También analizamos las declaratorias, su anotación en un registro provincial o municipal (en caso de haber sido creado en alguna jurisdicción) y las acciones estatales en torno a los bienes culturales.

En una segunda instancia, relevamos la normativa uruguaya sobre patrimonio cultural y las principales acciones estatales para su preservación.

Recién entonces, abordamos el análisis de las declaratorias del Tango y Payada, indagando sobre potenciales conflictos jurídicos y las vías pacíficas de solución.

\section{La conceptualización del patrimonio cultural inmaterial en los convenios internacionales}

La conceptualización del patrimonio cultural intangible se fue delimitando en las sucesivas asambleas generales de la UNESCO con el aporte de distintas disciplinas.

En una primera etapa se optó por una definición descriptiva de las manifestaciones culturales. En este sentido, la Declaración de México de $1982^{6}$ dijo que "comprende las obras de sus artistas, arquitectos, músicos, escritores y sabios, así como las creaciones anónimas, surgidas del alma popular, y el conjunto de valores que dan un sentido a la vida (...) la lengua, los ritos, las creencias...".

Posteriormente, se identificaron elementos comunes de esta categoría: la tradición y la expresión de identidad de un grupo humano. Siguiendo este criterio, la Recomendación de la Conferencia General de la UNESCO de $1989^{7}$ lo definió como "el conjunto de creaciones que emanan de una comunidad cultural fundadas en la tradición...”. Poco después, la "Carta de Shanghái” mencionó las particularidades de los pueblos (sus tradiciones, lenguas, festividades) como elemento característico.

\footnotetext{
Conferencia que tuvo lugar entre el 26/07/ al 06/08/1982.

Recomendación sobre la Salvaguardia de la Cultura Tradicional emitida el 15/11/1989. [Disponible en: http://portal. unesco.org/es/ev.php-URL_ID=13141\&URL_DO=DO_TOPIC\&URL_SECTION=201.html[ (Consultada el 20/11/2018).

$8 \quad$ Aprobada en la 7 a Asamblea regional de la Alianza regional del ICOM Asia-Pacífico Shanghái (China), 20 al 25/10/2002.
} 
En la Reunión de Expertos en Turín $(2001)^{9}$ se detalló el ámbito y formas de las manifestaciones culturales, mencionando, además de las tradiciones, la toponimia, artes escénicas, expresiones musicales y artísticas, prácticas sociales y religiosas, conocimientos de la naturaleza y el universo.

La Declaración de Estambul sobre el Patrimonio Cultural Inmaterial ${ }^{10}$ menciona otras características: la intangibilidad y la vulnerabilidad.

Finalmente, en el año 2003 se firmó la Convención de París para la salvaguardia del patrimonio Cultural Inmaterial ${ }^{11}$, entendiendo como tal, los usos, representaciones, expresiones, conocimientos que se transmiten de generación en generación siendo "recreado constantemente por las comunidades y grupos en función de su entorno, su interacción con la naturaleza y su historia, infundiéndoles un sentimiento de identidad y continuidad...."

Esta última definición resalta tres particularidades del patrimonio intangible: la identidad de un grupo humano, la espontaneidad de su expresión y la transmisión de generación en generación.

Teniendo en cuenta la conceptualización y delimitación contenida en los Acuerdos internacionales, podemos concluir que el patrimonio cultural inmaterial presenta los siguientes caracteres:

Inherencia, porque el patrimonio intangible está integrado por manifestaciones que expresan la identidad de un grupo humano, es decir, expresan su modo de ser (Labaca Zabala, 2013; Castro López \& Ávila Rodríguez, 2015, p. 94; Molina, 2018).

Intangibilidad, dado que los bienes culturales son incorpóreos expresando la creatividad, el simbolismo e identidad de un grupo humano.

Espontaneidad, porque se gestaron sin poder identificar el tiempo en que se iniciaron.

Dinamismo, porque el patrimonio intangible está vivo, produciéndose cambios internos (Labaca Zabala, 2012; Castro López \& Ávila Rodríguez, 2015, p. 95; Molina, 2018).

Vulnerabilidad, por la facilidad de sus desfiguraciones por factores externos (Castro López \& Ávila Rodríguez, 2015, pp. 94-96; Molina, 2018). Debe distinguirse el dinamismo propio de estas manifestaciones culturales y su vulnerabilidad. Por tanto, deben identificarse y catalogarse los cambios de las prácticas culturales relacionados con dinámicas internas del grupo social y descartarse las transformaciones producidas por factores exógenos no auténticos (Villaseñor Alonso \& Zolla Márquez, 2012; Molina, 2018, pp. 1-6).

Nosotros agregamos como característica del régimen jurídico del patrimonio intangible, la inexistencia de asignación de titularidad dominial pública o privada con la

9 Informe final, International Round Table on 'Intangible Cultural Heritage - Working Definitions', UNESCO, 07/03/2001, Turin, Italy. [Disponible en: http://www.unesco.org/culture/ich/es/eventos/mesa-redonda-deexpertos-sobre-el-patrimonio-cultural-inmaterial-definiciones-de-trabajo-00057] (Consultado el 18/11/2018).

10 Aprobada en la tercera Mesa Redonda de Ministros de Educación, el 17/09/2002.

11 Aprobada por la Conferencia General de la Organización de las Naciones Unidas para la Educación, la Ciencia y la Cultura (UNESCO), en su 32a reunión, celebrada en París del 29/09 al 17/10/2003. Esta Convención fue aprobada por la Ley Nacional N²6.118 sancionada el 05/07/2006 y publicada en el B.O No30.956 del $27 / 07 / 2006$. 
significación y el alcance establecido en el Código Civil. Los integrantes de la comunidad tienen derechos colectivos sobre las manifestaciones culturales y legitimación colectiva para demandar su protección siendo el objeto indivisible. Estos derechos no son ejercidos en forma exclusiva y excluyente por cada individuo sino como integrante de un grupo social.

En relación al patrimonio viviente, desde el punto de vista jurídico no puede asignarse titularidad (Molina, 2017), ya sean grupos humanos (comunidades aborígenes, comunidades de inmigrantes, comunidades de gauchos, payadores, etc.) o individuales. En efecto, siendo todo ser humano un sujeto de derecho y no objeto, no puede asignarse titularidad ni sobre estos grupos humanos ni sobre los individuos.

Las medidas de salvaguarda en las convenciones internacionales

En los acuerdos internacionales los Estados signatarios asumieron ciertos compromisos para la salvaguarda del patrimonio cultural intangible:

Primero, se comprometieron a crear oficinas u organismos administrativos competentes con potestades de gestión patrimonial, defensa, capacitación, sensibilización, fomento y difusión (entre ellas, inventariar, catalogar, documentar, actualizar).

Segundo, a sancionar normas legales y administrativas tendientes a esa finalidad.

Tercero, a financiar y promover la investigación científica sobre patrimonio cultural para la decantación de caracteres no autóctonos o que no sea una expresión fidedigna del grupo portador.

Cuarto, a capacitar personal idóneo y a formar expertos.

Quinto, a asegurar el respeto y difusión en la sociedad. A ese fin, deben adoptar medidas para sensibilizar a la población (como la inclusión en los planes educativos formales y no formales).

Sexto, a adoptar medidas para la prevención de la desfiguración de esas prácticas ancestrales por influencias externas.

Séptimo, a fomentar las manifestaciones culturales.

Octavo, a garantizar el acceso de toda la población al patrimonio cultural inmaterial.

En los siguientes capítulos analizaremos la legislación interna argentina para indagar en qué medida se ajusta a este marco jurídico internacional. También haremos una breve mención de la legislación uruguaya. Finalmente, individualizaremos los conflictos que pueden generarse en torno de bienes intangibles que se han desarrollado en dos o más Estados limítrofes. 
La protección del patrimonio intangible en el derecho argentino

El texto originario de la Constitución Nacional de 1853 no previó normas específicas sobre la cultura y protección del patrimonio histórico, artístico y documental. La reforma constitucional nacional de 1994, significó un avance en la protección del patrimonio cultural en nuestro país (Molina, 2017, p. 28; Endere, 2009, p. 40).

En primer lugar, impuso el deber al Estado de establecer normas de preservación del patrimonio cultural deslindando la competencia Nación-provincia en materia cultural. El art. 41, segundo y tercer párrafo de la CN dispuso: “Las autoridades proveerán a la protección de este derecho, a la utilización racional de los recursos naturales, a la preservación del patrimonio natural y cultural". Corresponde a la Nación "dictar las normas que contengan los presupuestos mínimos de protección, y a las provincias, las necesarias para complementarlas...”. En forma concordante, el art. 75 inc. 19, último párrafo, previó como atribución del Congreso Nacional, "dictar leyes que protejan la identidad y pluralidad cultural, la libre creación y circulación de las obras de autor, patrimonio artístico y los espacios culturales...".

La reforma constitucional introdujo una nueva especie de facultades concurrentes "dado que la Nación dicta leyes de presupuestos mínimos de tutela, las provincias tienen el deber de adecuar sus legislaciones a los mismos". Algunos autores la denominan "concurrencia complementaria maximizante" (Esain, 2009, pp. 263-291; Levrand, 2015).

En segundo lugar, la reforma de 1994 dio rango constitucional a Tratados Internacionales de Derechos Humanos que reconocen el derecho humano a la cultura (art. 75 inc. 22 de la Constitución Nacional).

Estos Tratados internacionales (art. 27 de la Declaración Universal de los Derechos Humanos; arts.15 inc. 1 a), 2 y 4 del Pacto Internacional de los derechos económicos, sociales y culturales) reconocieron a la cultura como derecho humano que comprende el derecho a participar y gozar de la vida cultural y a la protección de su obra artística.

Hasta el año 2006, solamente puede mencionarse como antecedente de protección del patrimonio cultural intangible, la Ley Nacional N²4.684 ${ }^{12}$ que declaró como bien patrimonial cultural nacional al género musical "Tango", previendo exenciones impositivas y normas de fomento y su difusión en el mundo que analizaremos detalladamente en los capítulos siguientes.

En el año 2006, se aprobó la Convención para la Salvaguardia del Patrimonio Cultural Inmaterial de 2003 mediante la Ley Nacional $N^{0} 26.118^{13}$, pero el Congreso Nacional no dictó una ley estableciendo los presupuestos mínimos aplicable en todo el país como lo exige el texto constitucional. En consecuencia, no existe en el ámbito nacional un régimen general de preservación, catalogación, mecanismos de actualización y difusión.

Más allá de este vacío normativo, se sancionaron algunas leyes nacionales que incorporaron ciertos bienes al patrimonio cultural inmaterial. Entre ellas, la Ley N $26.558^{14}$

\footnotetext{
Sancionada el 14/08/1996, publicada en el B.O N²8469, 02/09/1996.

Sancionada el 05/07/2006, publicada en el B.O No30956, 27/07/2006.

Sancionada el 18/11/2009, publicada en el B.O N³1807, 23/12/2009.
} 
que reconoció al género musical folclórico "Chamamé" como parte integrante del patrimonio cultural y estableció el Día Nacional del Chamamé, pero tampoco previó un régimen específico de preservación, catalogación, difusión ni medios de fomento como la exención impositiva.

Algunos años después, se sancionó la Ley $\mathrm{N}^{\circ} 27.332^{15}$ que declaró patrimonio cultural inmaterial de la Nación la Fiesta Nacional e Internacional del Poncho, que se realiza anualmente en la provincia de Catamarca, extendiéndolo a los usos, representaciones, expresiones, conocimientos y técnicas ancestrales, transmitidas de generación en generación, relativas al hilado y tejido artesanal de fibras provenientes de las especies animales autóctonas, vicuña, llama, alpaca y guanaco.

Recientemente, se ha sancionado la Ley $\mathrm{N}^{\circ} 27.381^{16}$ que declaró como parte integrante del patrimonio inmaterial argentino, a la Feria de las Artesanías y Tradiciones Populares Argentinas (conocida como Feria de Mataderos) que se celebra ininterrumpidamente en el barrio de Mataderos de la Ciudad Autónoma de Buenos Aires desde 1986.

La ausencia de una reglamentación general no impidió la gestión patrimonial nacional y provincial en pos de la difusión y reconocimiento internacional de algunos bienes culturales inmateriales.

Así, por ejemplo, desde el ámbito gubernamental se procuró la incorporación de la Payada como bien cultural del MERCOSUR y la incorporación del Tango y el Filete porteño a la Lista del Patrimonio Cultural Inmaterial de la Humanidad. En los años 2009 y 2015 respectivamente se cumplió ese anhelo, asumiendo un compromiso ante la UNESCO en la preservación, difusión y fomento de estos bienes culturales.

\section{El patrimonio cultural en el derecho público provincial}

En rigor, en la República Argentina la protección del patrimonio cultural inmaterial se inició en el derecho público provincial con la incorporación de cláusulas culturales en las constituciones provinciales reformadas después del año 1983 (Salta17, Jujuy ${ }^{18}$, San Luis ${ }^{19}$, de Río Negro ${ }^{20}$, Catamarca ${ }^{21}$ ), incluyendo disposiciones que previeron expresamente la salvaguarda del patrimonio cultural inmaterial. El mismo criterio adoptó la Constitución de Tierra del Fuego ${ }^{22}$ (provincia creada en el año 1990 por Ley $N^{\circ} 23.775$ ).

Sancionada el 23/11/2016, publicada en el B.O. N33527, 21/12/2016.

Sancionada el 07/09/2017, publicada en el B.O. N³3721, 02/10/2017.

Art. 52 de la Constitución de Salta (sancionada el 02/06/1986 y reformada parcialmente el 07/04/98).

Art. 65 Constitución de Jujuy sancionada el 22/10/1986.

Art. 67 y 258 inc. 17 de la Constitución de San Luis (sancionada el 14/03/1987).

Arts. 60 y 61 Constitución de Río Negro sancionada el 03/06/1988.

Arts. 264 y 265 y 252 inc. 10, de la Constitución de Catamarca, sancionada el 07/09/1988.

22 El art.60 de la Constitución de Tierra del Fuego sancionada el 17/05/1991, dispone: "El Estado Provincial promueve, protege y difunde las manifestaciones culturales, individuales o colectivas, que comprenden las costumbres, instituciones, creencias, actitudes y realizaciones del pueblo, que afirmen la identidad provincial, regional y nacional". 
Así por ejemplo, el art. 52 de la Constitución de Salta (1986) dice que el Estado “promueve las manifestaciones culturales, personales o colectivas y aquéllas que afirmen el sentido nacional y latinoamericano”. En otro párrafo agrega: “Las manifestaciones culturales y tradicionales de reconocido arraigo y trascendencia popular son protegidas y promocionadas por el Estado". Un texto semejante receptaron las Constituciones de San Luis (art. 67), de Río Negro (art. 61) y de Catamarca (arts. 264 y 265), todas anteriores a 1990.

Por su parte, la Constitución jujeña sólo menciona expresamente algunas manifestaciones culturales como el folclore y las artesanías (art. 65 inc. 4).

A partir de la reforma de la Constitución Nacional de 1994, varias provincias modificaron su texto constitucional local para adaptarlo al texto nacional (Neuquén, Santiago del Estero, La Rioja, Entre Ríos, Ciudad Autónoma de Buenos Aires, de La Pampa, de Chaco, Tucumán y Provincia de Buenos Aires, de Formosa ${ }^{23}$. Todas estas constituciones provinciales impusieron, al Estado provincial, el deber de preservación y difusión del patrimonio cultural inmaterial.

En este marco del derecho público provincial posterior a 1994, las provincias dictaron leyes o modificaron las normas vigentes previendo el patrimonio intangible. Asimismo, crearon registros para todos los bienes culturales y asignaron competencia a órganos administrativos específicos.

Por último, numerosos municipios -a los cuales se les reconoció su autonomía a partir de la reforma constitucional de 1994-, dictaron ordenanzas sobre patrimonio cultural.

Puede observarse que el régimen jurídico argentino sobre patrimonio cultural es complejo y disperso. Esta peculiaridad se acentúa en relación a los objetos intangibles. Existen normas comunitarias, nacionales, provinciales y municipales con competencia cultural.

\section{El patrimonio cultural inmaterial en la legislación argentina}

Ya hemos mencionado que el Congreso Nacional no ha dictado una ley $^{24}$ previendo presupuestos mínimos uniformes para todas las provincias sobre individualización, catalogación, actualización, valorización, preservación, difusión y fomento. Ni siquiera ha organizado ni reglamentado un registro nacional de bienes intangibles como existe en relación a los bienes culturales materiales. La Ley Nacional N26.118 solamente aprobó la Convención de París de 2003.

23 Arts. 105 y 106 de la Constitución de Neuquén sancionada el 29/11/1957, enmendada el 20/03/1994, reformada el 17/02/2006; arts. 35, 64 y 65, 136 inc. 31 de la Constitución de Santiago del Estero del 25/11/2005; art. 58 de la Constitución de La Rioja sancionada el 14/05/2008; arts. 26, 240 incs. 22 y 23 de la Constitución de Entre Ríos sancionada el 03/10/2008; arts. 27 inc. 2, 32, 81 inc. 8 de la Constitución de la Ciudad Autónoma de Buenos Aires sancionada el 01/10/1996; art. 19 de la Constitución de La Pampa sancionada el 06/10/1960, reformada el 06/10/1994. Arts. 78 y 84 de la Constitución de Chaco del 27/10/1994. Art. 44 de la Constitución de la Provincia de Buenos Aires sancionada el 13/09/1994. Art. 92 de la Constitución de Formosa, sancionada el 07/07/2003. Art. 145 de la Constitución de Tucumán sancionada el 06/06/2006.

24 En la Cámara de Senadores hay un proyecto (S-0721/12) que hasta la fecha no ha sido sancionado [en línea: www.senado.gov.ar/parlamentario/parlamentaria/315328/downloadPdf (consultado 19/11/2018)] 
Algunas provincias se han limitado a adherir a la Ley Nacional N²6.118 (como la Ley $\mathrm{N}^{\circ} 1.513$ de Formosa sancionada el 20/09/2007), sin establecer normas específicas para estos bienes culturales.

Otras han sancionado normas generales para los bienes culturales, incluyendo a los objetos incorporales; sin embargo, muy pocas provincias han previsto normas especiales para el patrimonio cultural inmaterial (entre ellas, la Ley N6.193 de Corrientes ${ }^{25}$ ).

También, algunos municipios han aprobado ordenanzas estableciendo un régimen sobre patrimonio cultural (material e intangible), tales como la Ordenanza $\mathrm{N}^{\circ} 12.241 / 13^{26}$ de la Ciudad de Córdoba; Ordenanza N ${ }^{\circ} 981 / 17^{27}$ de Nono-Cba; Ordenanza N ${ }^{\circ} 10075 / 95$ del Partido General Pueyrredón-Bs.As. ${ }^{28}$; Ordenanza N ${ }^{\circ} 14.298 / 14^{29}$ de Tandil-Bs.As.; Ordenanza $\mathrm{N}^{\circ}$ 2588/93 de la Municipalidad de San Fernando del Valle-Catamarca ${ }^{30}$; Ordenanza N ${ }^{\circ} 8.388 / 17$ de Guaymallén ${ }^{31}$; Ordenanza N¹.741/18 ${ }^{32}$ San Carlos-Mza. Incluso, algunas comunas ya habían dictado ordenanzas sobre esta temática hacia el año 1985 como la Municipalidad de Comodoro Rivadavia (Cisellia, Hernández \& Duplattc, 2018).

Estas normas locales crearon organismos administrativos con competencia cultural y han incluido los siguientes bienes incorpóreos:

1. Las expresiones y manifestaciones intangibles de la cultura. Incluye las tradiciones, las costumbres y los hábitos de la comunidad, espacios o forma de expresión de la cultura popular de valor histórico, artístico, antropológico o lingüístico vigentes o en riesgo de desaparición, incluyendo rituales, costumbres, festividades populares, oficios, conocimientos, creencias, usos (art. 4 inc. j de la Ley N ${ }^{\circ} 5.556$ de Chaco ${ }^{33}$, el art. 4 inc. j de la Ley $\mathrm{N}^{\circ} 1.227^{34}$ de la Ciudad Autónoma de Bs.As., el art. 7 incs. a, b, c, d y e de la Ley $\mathrm{N}^{\circ} 4.843^{35}$ de Catamarca, el art. 3 inc. d de la Ley $\mathrm{N}^{\circ} 6.801^{36}$ de San Juan, los arts. 1 y 2 de la Ley $\mathrm{N}^{0} 9.729$ de Córdoba ${ }^{37}$, el art. 3 inc. j de la Ley $\mathrm{N}^{0} 2.083^{38}$ de La Pampa, el art. 8 inc. c. 7 de la Ley $\mathrm{N}^{\circ} 3.656^{39}$ de Río Negro, art. 4 inc. j de la Ley $\mathrm{N}^{\circ} 5.751^{40}$ de Jujuy, el art. 3 inc. d) de la Ley $\mathrm{N}^{0} 7.500^{41}$ de Tucumán.

Sancionada el 25/04/2013.

Sancionada el 07/11/2013.

Sancionada el 22/09/2017.

Sancionado el 10/08/1995.

Sancionada el 23/10/2014.

Emitida el 12/08/1993.

Sancionada el 24/08/2017.

Sancionada el 27/09/2018, publicada en el B.O 31/10/2018.

Sancionada el 18/05/2005, publicada en el B.O 17/06/2005.

Sancionada el 04/12/2003, publicada en el B.O 05/01/2004.

Sancionada el 06/07/1995, publicada en el B.O 15/08/1995.

Sancionada el 26/06/1997, publicada en el B.O 06/10/1997.

Sancionada el 29/12/2009, publicada en el B.O 20/01/2010.

Sancionada el 26/11/2003, publicada en el B.O 16/01/2004.

Sancionada el 29/11/2007, publicada en el B.O 10/01/2008.

Sancionada el 14/12/2012, publicada en el B.O 09/01/2013.

Sancionada el 29/12/2004, publicada en el B.O 02/02/2005 (deroga la Ley N4.593). 
En la República Argentina, además del Tango, Filete porteño (Patrimonio Cultural Inmaterial de la Humanidad), Payada, Mate, Chamamé (Patrimonio Cultural de, MERCOSUR), la Fiesta del Poncho y la Feria de las Artesanías de Mataderos (Patrimonio Nacional), hay un sinnúmero de bienes intangibles provinciales y municipales.

Entre ellos, el Gobierno de la Ciudad Autónoma de Buenos Aires ha declarado como patrimonio inmaterial al personaje "Clemente” (Ley N¹.383), "Mafalda” (Ley N¹.721), el filete porteño (Ley N¹.941), Teatro independiente (Ley N².064), Banda Sinfónica y Partituras de la Ciudad de Bs.As. (Ley No3.547), Feria de Mataderos (Ley No3.835), Muralismo urbano (Ley No4.028); Género teatral revista porteña (Ley N4.771). Esta Ciudad fue pionera en declaratorias de bienes culturales inmateriales, siendo algunas anteriores a la Ley Nacional $\mathrm{N}^{\circ} 26.118$ (2003), como la Ordenanza $\mathrm{N}^{\circ} 52.039 / 97^{43}$ que declaró patrimonio cultural "la actividad que desarrollan las agrupaciones de carnaval".

En algunas provincias ha habido una gestión gubernamental tendiente a identificar y valorizar el patrimonio intangible. La Ley N $6.193^{44}$ de Corrientes declaró como bienes culturales inmateriales a los actos en honor a la Virgen de Itatí y Virgen de la Merced, San Juan Bautista y del Milagro de la Cruz, los actos patronales de las localidades y las fiestas del "Gaucho Gil”.

En la provincia de Mendoza se ha presentado una situación paradójica. La Ley provincial N6.034 no menciona a los bienes intangibles. Por su parte, el Decreto N¹.882/2009 solamente hace una fugaz mención de éstos sin establecer normas para su preservación, catalogación, actualización, registro, difusión. Sin embargo, se ha declarado como bienes intangibles a la Tonada Cuyana ${ }^{45}$, la "Fiesta de la Vendimia" (incluyendo las fiestas barriales y distritales, la Bendición de los Frutos, Carrusel, Vía Blanca y Acto Central ${ }^{46}$ y mediante la Ley №.806 ${ }^{47}$ se ha adherido a la Ley $N^{\circ} 24.684$ (que declaró al Tango como patrimonio cultural).

Las municipalidades tienen una larga lista de bienes culturales inmateriales. Entre ellos, los pesebres de San Salvador de Jujuy (Ordenanza No6.423/12); la Feria de las Provincias (Ordenanza N¹3.363/17 de Comodoro Rivadavia); la Cabalgata de los Claveles, la Serenata, el Rial, la Fiesta Provincial de la Tradición, la Fiesta del Agua y la Producción, la Fiesta Nacional del Orégano (Ordenanza N ${ }^{\circ} .741 / 18^{48}$ de San Carlos, Mendoza); la obra de Draghi Lucero (Ordenanza N $8.270 / 16^{49}$ de Guaymallén, Mendoza); la Peregrinación de la Virgen de la Carrodilla (Decreto No638/14 de la Municipalidad de Luján de Cuyo ${ }^{50}$ ).

2. El patrimonio cultural viviente. Se refieren a este objeto, las Leyes $\mathrm{N}^{\circ} 5.556$ de Chaco (art. 4 inc. k), N5.751 de Jujuy (art. 4 inc. r), N¹.227 de la Ciudad Autónoma de

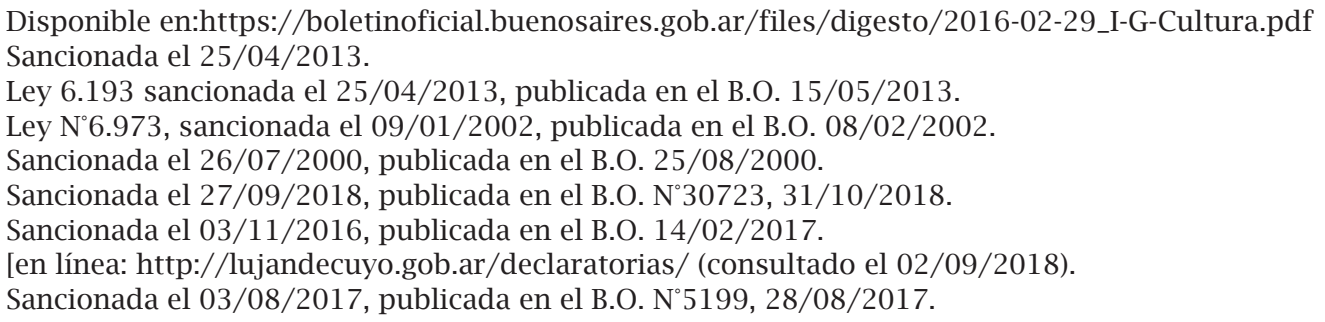


Buenos Aires (art. 5), Nº2.083 de La Pampa (art. 3 inc. k).

El patrimonio cultural viviente está encarnado en las personas que lo crean, recrean y transmiten mediante sus expresiones orales y gestuales.

No sólo la cultura y tradiciones indígenas son protegidas sino también la criolla y la cultura de los inmigrantes de distintos países. Así, por ejemplo, la provincia de Tucumán, a través de la Ley N7.643/05, instituyó el día del Patrimonio Cultural Árabe; Ley N $\mathrm{N}^{\circ} .852^{51}$ de la Ciudad Autónoma de Buenos Aires declaró como patrimonio viviente a 36 colectividades.

También, se ha declarado como "Patrimonio Cultural Viviente" a individuos ilustres y testimonios únicos de la historia o tradición. Entre ellos, la Resolución N¹73/18 ${ }^{52}$ del Senado de Salta que declaró como patrimonio cultural artístico viviente de La Poma a la Sra. Eulogia Tapia; también, Ley $\mathrm{N}^{\circ} 14.134^{53}$ de la provincia de Buenos Aires que declaró patrimonio viviente a la Sra. Ercilla Moreira de Cestac (testimonio cultural de los indios pampas).

Por último, se han declarado patrimonios culturales vivientes a grupos artísticos como el Coro Qom Chelaapí (mediante Ley N${ }^{\circ} 1.484$-ex N5.778- de Chaco ${ }^{54}$ ).

\section{Análisis crítico de la legislación argentina sobre patrimonio cultural inmaterial}

En la República Argentina, el régimen de salvaguarda del patrimonio cultural intangible es disperso. La existencia de distintas órbitas de gobierno con competencia en materia cultural en el marco de nuestro régimen constitucional, torna más complejo el sistema normativo; especialmente por la falta de mecanismos de articulación y coordinación (Endere, 2007, p. 33).

La Ley N²6.118 se ha limitado a aprobar el Convenio de París de 2003 pero no ha establecido un régimen especial para el patrimonio intangible, previendo contenidos mínimos para toda la Nación como lo exige el art. 41 de la CN.

En el derecho público provincial, este régimen jurídico es escueto, con amplias lagunas normativas y con remisiones sin sentido o erróneas. Varias provincias regularon los bienes inmateriales dentro de un régimen general de patrimonio cultural, sin tener en cuenta que muchas normas del patrimonio cultural material (como las restricciones al dominio que prohíben vender u obligan a su exhibición) no pueden aplicarse al patrimonio cultural viviente (Molina, 2017, pp. 54-56). En efecto, el patrimonio viviente (grupo humano) es sujeto de derecho y no objeto.

\footnotetext{
Aprobada el 02/08/2018 Expte. №0-27.141/18.

Sancionada el 19/05/2010, publicada en el B.O. N²6396, 15/07/2010.

Sancionada el 06/09/2006, publicada en el B.O. N8528, 06/10/2006.

54 Es sancionado/a con una multa quien “....destruya, obstaculice, perturbe o impida las expresiones, manifestaciones intangibles y/o Patrimonio Cultural Viviente, declaradas en los términos de la Ley $\mathrm{N}^{\circ} 1.227$ y desarrolladas dentro del marco regulatorio de la actividad y/o del uso del espacio público". Sección 12.1.2 inc.f) de la Ley N4.830 Sancionada el 05/12/2013 BOCBA N4321, 20/01/2014.
} 
En general, la legislación provincial prevé pocas disposiciones aplicables a los objetos incorpóreos referidas básicamente a la asignación de competencia de la autoridad administrativa y al fomento. Sin embargo, no han establecido normas sancionatorias para asegurar su coercibilidad.

Excepcionalmente, algunas provincias han previsto algunas normas sancionatorias aunque insuficientes, sancionando solamente las conductas que obstruyen o impiden su desenvolvimiento (entre ellas, el art.12 pto.1 inc.f) de la Ley N4.830 de la Cdad Autónoma de Bs.As ${ }^{55}$. Sin embargo, no contienen disposiciones que impongan sanciones por falta de respeto o por uso desleal por un tercero siendo ésta última una de las facetas que mayor preocupación ha generado en los organismos internacionales como la UNESCO y WIPO.

En efecto, que la $\mathrm{OMPI}^{56}$ y la UNESCO han trabajado en las últimas décadas para establecer un régimen especial para la identificación, documentación, preservación, difusión y fomento de estas prácticas tradicionales, la protección frente al uso desleal por terceros y la participación equitativa de los beneficios a favor de los grupos culturales (vigésimo primera y vigésimo segunda sesión del Comité Intergubernamental sobre Propiedad Industrial y Recursos Genéticos y Conocimientos Tradicionales (12 al 16 de febrero de 2012 y 9 al 13 de julio de 2012 respectivamente) (Molina, 2018, p. 143).

Por otro lado, existe un déficit comunicacional en relación a la declaratoria de bienes como patrimonio cultural intangible. No sólo no existe un registro nacional de bienes intangibles (que centralice los bienes declarados en la Nación, provincias y municipios o establezca links con los registros locales) ni una base de datos exhaustiva y actualizada de acceso público, sino también se ha omitido la publicidad de los antecedentes que justificaron la declaratoria. Pocas provincias y municipios han incorporado en la página web oficial la enumeración de bienes declarados como patrimonio cultural mencionando la declaratoria, exhibiendo algunas fotografías y dando a conocer algún relevamiento local, pero omiten otros datos (declaratorias y acciones de preservación, rescate y fomento de cada órbita de gobierno).

La falta de publicidad puede llevar a la superposición de acciones gubernamentales e impedir el control ciudadano de la gestión cultural.

En estos aspectos queda mucho camino por transitar.

Por un lado, el Congreso Nacional debe sancionar una ley de presupuestos mínimos sobre patrimonio cultural intangible para todo el país, previendo un registro nacional de

55 “Propiedad intelectual y Expresiones Culturales Tradicionales o Folclore”, ver: Folleto 1, publicación nº 913 (S), en: http://es.scribd.com/doc/6445427/Propiedad-intelectual-y-expresiones-culturalestradicionales-o-del-folcloreFolleto-N-1. Fecha de consulta: 10/10/2016. Ver también: "Informe final sobre las expresiones nacionales en materia de protección jurídica de las expresiones del folclore” (Documento WIPO/GRTKF/IC/3/10); "Análisis consolidado de la protección de las expresiones culturales tradicionales" (Documento WIPO/GRTKF/IC/5/3; "Las expresiones culturales tradicionales/expresiones del folclore: opciones políticas y jurídicas” (Documento WIPO/ GRTKF/IC/6/3.

56 Promulgada el 20/10/2006, publicada en el D.O. 31/10/2006. 
acceso público libre y gratuito; también, mecanismos de coordinación de las acciones de los distintos niveles de gobierno. Debe tenerse presente, que el art. 12 inc. 1 de la Convención para la salvaguarda del patrimonio cultural intangible (París, 2003) exige a cada país labrar un inventario de los bienes culturales existentes en todo el territorio. Por su parte, el art. 13 inc. d) de esa Convención exige documentar y registrar.

Estas normas jurídicas deben prohibir el uso indebido y desleal por terceros como así también todas aquellas conductas que afecten su autenticidad y menoscaben su tipicidad.

Por otro lado, cada provincia debe prever normas específicas para estos bienes culturales inmateriales en razón de sus características peculiares en su ámbito territorial. Particularmente debe crear un registro provincial de acceso libre y una base de datos exhaustiva, estableciendo formas y requisitos uniformes para la actualización. También, debe prever mecanismos de coordinación de las actividades desarrolladas por los municipios y gobierno provincial, establecer un régimen sancionatorio y medios generales de fomento cultural.

Finalmente, los municipios deben establecer normas específicas y un registro municipal, pero fundamentalmente deben prever la coordinación de la acción en relación a bienes culturales originarios o desarrollados en un contexto geográfico que comprenda dos o más comunas.

Teniendo en cuenta que las investigaciones científicas se desarrollan en el ámbito universitario y en otros centros y entes públicos y privados, es recomendable que se suscriban convenios de colaboración recíproca para que la actividad gubernamental se nutra del resultado de éstas.

Este aspecto es muy importante, especialmente si se tiene en cuenta que algunas declaraciones emitidas por los órganos legislativos de nuestro país no reúnen antecedentes exhaustivos sino que se fundan en peticiones de referentes locales. Por eso, nosotros propugnamos que cada proyecto de ley y actos administrativos en relación a cada bien cultural, sea encabezado por una investigación científica.

\section{El patrimonio cultural intangible en la legislación uruguaya}

En este país, la Ley $\mathrm{N}^{\circ} 18.035^{57}$ aprobó la Convención para la Salvaguardia del Patrimonio Cultural Inmaterial, hecha el 17 de octubre de 2003, pero hasta la fecha no ha sancionado una reglamentación general para los bienes culturales intangibles, por tanto, no hay régimen sancionatorio ni normas que protejan en contra de la competencia desleal o uso indebido por terceros.

No obstante, el Decreto №414/2010 declaró como patrimonio inmaterial de ese Estado las siguientes expresiones culturales:

57 Nominación 00258- inscripción a.com.13.01 aprobada el 02/10/2009 (disponible en: https://ich.unesco.org/es/ RL/el-tango-00258) (consultada el 20/11/2018). 
- El arte del payador.

- El toque de "llamada" de los tamboriles afromontevideanos y candombe.

- La murga montevideana como expresión multifacética, la "marcha camión”, el “candombeado" y la "murga-canción".

- La especie musical y lírica conocida como estilo o triste.

- El tango, en tanto especie musical, lírica y coreográfica.

- La milonga en sus distintas vertientes, especialmente la milonga uruguaya (oriental) y la achamarrada.

Dos bienes culturales de este país han sido incorporados a la Lista del Patrimonio Cultural Inmaterial de la Humanidad (ambos en el año 2009): el Candombe (Decisión 4.COM 13.74 de la UNESCO) y el Tango (Decisión 4.COM 13.01).

\section{El caso emblemático del tango como patrimonio cultural inmaterial}

En el año 2009 se incorporó el Tango a la Lista del Patrimonio Cultural Inmaterial de la Humanidad ${ }^{9}$. Fue el primer objeto intangible originario del Río de la Plata que obtuvo este reconocimiento y fue inscrito como manifestación cultural de dos países limítrofes: Argentina y Uruguay.

Es importante resaltar algunos aspectos jurídicos preliminares:

\section{Primero, la incorporación a esta Lista del Patrimonio Cultural Inmaterial de la Humanidad fue un largo proceso que se inició en cada país y transitó diversas etapas.}

El primer paso para la valorización, sensibilización y difusión del Tango se remonta al año 1977. La Municipalidad de la Ciudad de Buenos Aires mediante el Decreto No5.830/7759 estableció el 11 de diciembre como "Día del Tango", en homenaje al natalicio de dos grandes figuras como fueron Carlos Gardel (1890) y Julio De Caro (1899), aunque con vigencia únicamente en la Capital Federal. Unos días más tarde, el PEN emitió el Decreto №3.781/7760 fijando esa fecha como Día Nacional del Tango.

En el año 1996 la Ley Nacional N²4.68461 declaró como bien patrimonial nacional al “Tango”, incluyendo la música, danza y representaciones plásticas alusivas. Además, declaró de interés nacional la promoción y difusión, las investigaciones científicas e históricas, la conservación de documentos, objetos, lugares y monumentos que guarden relación significativa con sus expresiones y con sus destacados creadores e intérpretes; la edición literaria, musical o audiovisual; las exposiciones de artes y los festivales musicales. Asimismo, previó una desgravación impositiva de dichas actividades y un régimen preferencial aduanero

Emitido el 29/11/1977.

Emitido el 19/12/1977.

Sancionada el 14/08/1996, publicada en el B.O. 02/09/1996.

Emitido el 04/06/98, publicado en el B.O. N²8914, 10/06/1998. 
para instrumentos musicales y publicaciones referidas al Tango.

Es importante resaltar que esta declaración del Tango como bien cultural fue pionera en nuestro país, dado que fue anterior a la Convención internacional de París sobre patrimonio intangible (2003) y anterior a la legislación nacional sobre bienes culturales.

Poco después, el Decreto Nacional No627/9862 adoptó medidas tendientes a un relevamiento de bienes muebles e inmuebles sobre el Tango y al seguimiento de la observancia de la ley. Entre las medidas administrativas, debía requerirse periódicamente informes a las Embajadas del país sobre la difusión del Tango en el exterior.

En el año 2005, la Ley N²6.046 ${ }^{63}$ estableció la Semana Nacional del Tango, comprendida entre los días 11 y 18 de diciembre de cada año.

El gobierno autónomo de la Ciudad de Buenos Aires también tuvo diversas iniciativas políticas vinculadas a la preservación patrimonial y la promoción del Tango simultáneamente a la gestión gubernamental nacional. En el año 1989, el Concejo Deliberante sancionó la Ordenanza N43.156 $6^{64}$ que instituyó el concurso anual "Certamen Municipal de Tango Hugo del Carril”.

En el año 1998, la Legislatura de esa Ciudad sancionó la Ley N ${ }^{\circ} 130 / 98^{65}$ declarando al Tango como bien intangible de la Ciudad y garantizando la preservación, recuperación, difusión en el país y en el extranjero, su promoción e investigación. Por la misma ley, se creó la Fiesta Popular del Tango que se festeja en forma anual y cuya culminación coincide con el día conmemorativo de este género cultural.

Esta ley local bonaerense (1998) es posterior a la ley nacional (1996), sin embargo impuso al gobierno local numerosos deberes tendientes a preservar su intangibilidad. Por ejemplo, respetar emplazamientos arquitectónicos y urbanísticos emblemáticos; ambientar espacios públicos de la Ciudad; preservar el bandoneón y los instrumentos musicales que pertenecieron a grandes intérpretes. Además, impuso el deber de organizar o patrocinar eventos y exposiciones alusivas. Y por último, impuso el deber de promover el valor turístico del Tango, siendo éste el aspecto que generó más debate y oposición ${ }^{66}$.

Segundo, el Tango se inició en los suburbios del conurbano bonaerense pero hoy se ha extendido a todo el territorio argentino.

Si bien el Tango se inició en los suburbios del conurbano bonaerense, el mismo se difundió en todo el país, particularmente después de la sanción de la Ley Nacional N²4.684 y la incorporación a la Lista del Patrimonio Cultural Inmaterial de la Humanidad.

62 Sancionada el 08/06/2005, publicada en B.O. N³0690, 07/07/2005.

63 Emitido el 14/12/1988, publicada en B.M. No $18443,05 / 01 / 1989$.

64 Sancionada el 14/12/1998, publicada en el B.O.C.B.A. N616, 22/01/1999.

65 Algunos grupos autodenominados "Autoconvocados por el tango" manifestaron su disconformidad con esa finalidad utilitaria, sosteniendo que "debía resaltarse el valor simbólico, conmemorativo y participativo”. Morel, Hernán. "La meca del tango: procesos de activación, megaeventos culturales, turismo y dilemas en el patrimonio local”, [Disponible en: http://ri.conicet.gov.ar/bitstream/handle/11336/28782/CONICET_Digital (consultado el $16 / 11 / 2018)]$

66 Sancionada el 26/07/2000, publicada en B.O 25/08/2000. 
Algunas provincias han adherido expresamente, entre ellas, la provincia de Santa Fe mediante la Ley Provincial $N^{\circ} 12.815$ y la provincia de Mendoza mediante la Ley $N^{\circ} 6.806^{67}$. En el marco de esa legislación provincial, algunos municipios han implementado programas de difusión y promoción, como el Programa el Tango en el Barrio (Ciudad de Santa Fe), el rubro "Salón Milonga” (Rosario ${ }^{68}$ ), el "Tango por los caminos del vino" (Mendoza), "Programa San Rafael y el Tango"69.

\section{Tercero, este género musical y baile se originó y desarrolló en un ámbito geográfico limítrofe.}

El Tango es un bien cultural, producto de la confluencia de varias culturas, que se originó y desarrolló en un ámbito espacial delimitado que conforma el territorio de dos Estados limítrofes: Argentina y Uruguay. Los gobiernos de ambos Estados realizaron una gestión cultural tendiente a su valorización y difusión durante varios años.

En los párrafos precedentes mencionamos el proceso jurídico y las políticas culturales del Gobierno de la Ciudad Autónoma de Bs.As. y Gobierno Nacional, que culminó con la sanción de la Ley Nacional N²4.684.

En la República de Uruguay hubo un proceso similar aunque posterior. En el año 1998, la Ley $\mathrm{N}^{\circ} 16.905^{70}$ declaró Himno Cultural y Popular de la República Oriental del Uruguay a "La Cumparsita”, creada por el uruguayo Gerardo Hernán Matos Rodríguez y estrenada en Montevideo, el 19 de abril de 1917. En el año 2007, se estableció como "Día Uruguayo del Tango" el 5 de octubre de cada año mediante la Ley №18.10771.

En el año 2010 se dictó la Resolución N ${ }^{\circ} 414^{72}$ que declaró patrimonio cultural al Tango y la Milonga Oriental. Poco después, se creó una Comisión Interministerial de Apoyo al Tango ${ }^{73}$, en la órbita del Ministerio de Educación y Cultura que tuvo como objetivo, su difusión y promoción de la investigación. También, por Ley No $19.464^{74}$ se declaró el año 2017 como año de la celebración del "Centenario de la Cumparsita”.

\section{Cuarto, teniendo en cuenta la incorporación del Tango en la Lista del Patrimonio} Cultural Inmaterial de la Humanidad ambos países se han comprometido a realizar acciones tendientes a su preservación, catalogación, investigación, difusión.

Este compromiso internacional torna conveniente la coordinación de acciones estatales y medidas administrativas en pos del mismo objetivo, evitando que se neutralicen mutuamente o contrarresten perjudicando la preservación del bien intangible.

67 Ordenanza N ${ }^{\circ} 8.187$ del 14/06/2007.

68 Ordenanza N¹1.549 sancionada el 07/04/2014, publicado en el B.M. N¹97, 14/05/2014.

69 Sancionada el 02/01/1998, publicada en el D.O. 20/01/1998.

70 Sancionada el 14/03/2007, publicada en el D.O. N²7216, 12/04/2017.

71 Emitida el 04/03/2010, publicada en el D.O. 22/03/2010.

72 Decreto No 257/2012 emitido el 10/08/2012, publicado 21/08/2012.

Sancionada el 14/12/2016, publicada en el D.O. N²9616, 04/01/2017.

74 Dossier candidatura la Payada [Disponible en: http://www.mercosurcultural.org/attachments/article/107/ dossier-la-payada.pdf] (consultada el 26/11/2018). 


\section{La payada}

El 6 de diciembre de 2012 se creó la categoría Patrimonio Cultural del MERCOSUR aprobada mediante la Decisión CMC N055/12 (modificada por la Decisión CMC No21/14). La primera manifestación intangible incluida en la Lista fue la "Payada", aprobada en la XI Reunión de la Comisión de Patrimonio Cultural del MERCOSUR (29/05/2015, Brasil -Acta $\left.\mathrm{N}^{\circ} 01 / 2015\right)$.

La Payada tiene una importancia identitaria en los países del MERCOSUR. "El arte de la Payada es una práctica anterior al nacimiento de los actuales estados del cono sur de América, cuyo origen se remonta al S. XVIII (...) En la actualidad se trata de una manifestación de identidad cultural común a tres países fundadores del Mercosur, que encuentra relaciones y similitudes con diversas formas artísticas de la región, emparentadas con el canto improvisado"75.

Algunos Estados miembros dedican un día al año a homenajear la Payada, en honor al nacimiento de sus payadores más célebres (24 de agosto ${ }^{76}$ en Uruguay, 30 de enero ${ }^{77}$ en Rio Grande do Sul). En Paraguay la tradición de la Payada se rescata cada año en los festejos de la localidad sureña de Santiago de Misiones. También, es una práctica cultural conocida en el centro de Chile donde se denomina "paya" (aunque no es un Estado miembro del MERCOSUR sino sólo asociado). En este país, mediante el Decreto $N^{\circ} 131 / 2017^{78}$ se estableció el 30 de julio como día conmemorativo. En Argentina, se instituyó el 23 de julio como Día del Payador; primero en la Ciudad Autónoma de Buenos Aires mediante Decreto Nº.256/1986. Poco después, el Decreto Provincial N 2.180/1991 extendió su alcance territorial a toda la provincia de Buenos Aires; un año más tarde, la Ley Nacional $N^{\circ} 24.120^{79}$ lo extendió a todo el territorio nacional.

Algunos municipios avanzaron aún más en la valorización de la Payada. En este sentido, la Resolución N576/2012 del Partido de San Vicente (Buenos Aires) declaró la Payada como Patrimonio Cultural Inmaterial Municipal.

Por su parte, en el Uruguay, la Resolución N²25/2010 del Ministerio de Educación y Cultura declaró "el arte del Payador" como Patrimonio Cultural Inmaterial del país tanto en su improvisación individual, como en su expresión máxima la Payada de contrapunto.

\section{Algunas lagunas normativas en las declaratorias del tango y payada como bienes culturales}

Más allá de la inexistencia de un régimen general para el patrimonio cultural intangible, las leyes que declaran el Tango y la Payada como patrimonio cultural intangible contienen algunas disposiciones escuetas pero quedan amplios vacíos normativos. Estas leyes

75 Ley $N^{\circ} 16.764$ sancionada el 15/08/1996, publicada en el D.O. 29/08/1996.

76 Ley $N^{\circ} 11.676$ sancionada el 16/10/2001, publicada en el D.O.E. N ${ }^{\circ} 198,17 / 10 / 2001$ [Disponible en: http://www. al.rs.gov.br/legis/M010/M0100018.asp?Hid_IdNorma=1644\&Texto=\&Origem=1] (consultada el 20/11/2018).

77 Emitido el 28/06/2017, publicado en el B.O. 03/8/2017.

78 Sancionada el 19/08/1992, publicada en el B.O. N ${ }^{\circ} 27471,14 / 09 / 1992$.

79 [Disponible en: https://www.wipo.int/treaties/es/ShowResults.jsp?treaty_id=15] (Consultada el 21/11/2018). 
básicamente asignan competencia a la autoridad administrativa y le impone algunos deberes; sin embargo, omiten aspectos esenciales para su efectividad y coercibilidad.

Primero, las normas (no sólo las leyes generales sobre patrimonio cultural sino también las leyes que declararon al Tango y Payada como patrimonio cultural nacional), omiten establecer reglas que aseguren la preservación de la autenticidad de esta manifestación cultural, evitando o previniendo la generalización que le haga perder identidad.

Este aspecto es relevante en relación al Tango por su gran difusión en el país y en el extranjero.

Es cierto que las manifestaciones intangibles son esencialmente dinámicas; por ello, deben preverse mecanismos para actualizar las manifestaciones culturales identificando las causas exógenas y endógenas, pero ello no implica que cualquier alteración o cambio deba considerarse auténtico. De lo contrario, podrían generalizarse de tal modo que pierdan identidad.

Segundo, esas mismas normas jurídicas no prevén medidas tendientes a impedir el uso indebido y desleal por terceros. En el marco jurídico vigente, frente a la inexistencia de normas que prohíban y sancionen el uso indebido y desleal, cualquier persona podría imitar y explotar una manifestación cultural. Así por ejemplo, cualquier persona podría incluir ritmos típicos del Tango en una composición musical cualquiera sea su género, sin las limitaciones del régimen de propiedad intelectual.

La práctica desleal genera beneficios económicos a quien imita o copia sin compensación a la comunidad donde la manifestación cultural ha nacido y desarrollado; pero además puede llevar a la vulgarización y pérdida de identidad de esa manifestación cultural.

Tercero, en general estas normas jurídicas que declararon el Tango y la Payada como patrimonio cultural, omiten establecer un régimen sancionatorio o es escueto e insuficiente. Debe tenerse presente que la existencia de un régimen sancionatorio es indispensable para asegurar la coercibilidad. De lo contrario, las declaratorias de bienes culturales serían una mera declaración de deseo de divulgación cultural sin consecuencias jurídicas.

Cuarto, en la mayoría de los casos las declaratorias de los bienes culturales son emitidas sin tener claro sus objetivos y la finalidad.

Hemos mencionado la proliferación de declaratorias del Tango y Payada como bien cultural en el ámbito municipal, provincial y nacional, reiterándose y superponiéndose unas a otras sin coordinación alguna y sin definirse metas y objetivos. La claridad y definición de los objetivos permitirá adoptar medidas adecuadas y facilitará la coordinación de las acciones por los distintos niveles gubernamentales en Estados federales y en los Estados miembros del MERCOSUR.

En algunos casos, la declaratoria como Patrimonio de la Humanidad se ha usado como estrategia de marketing del bien cultural a los fines del fomento turístico o industria cultural. En este sentido, la Ley $\mathrm{N}^{\circ} 130 / 98$ de la Ciudad de Bs.As. menciona la finalidad turística pero hay otras olvidadas o relegadas. 
Por su parte, la incorporación a la Lista del Patrimonio Cultural Inmaterial de la Humanidad o la Lista del MERCOSUR no tiene un fin en sí mismo. En rigor, la declaratoria como patrimonio cultural tiene como finalidad la salvaguarda, preservación, recuperación, catalogación, investigación, fomento y difusión mundial, pero también implica que el Estado asume compromisos con la ONU y UNESCO de ejecutar políticas para cumplir con esos objetivos más allá del interés turístico.

\section{Algunos conflictos jurídicos en relación a bienes culturales in materiales regionales}

Los conflictos en torno a bienes culturales originados en áreas de frontera se producirán especialmente por la inexistencia de un registro nacional y regional con una base de datos amplia y actualizada de acceso público que permita conocer las normas jurídicas, antecedentes y actos administrativos emitidos en torno a cada bien cultural no sólo nacional sino también, provincial y municipal. Sin la existencia de este registro no es fácil conocer la delimitación y alcance del bien declarado como patrimonio cultural, ni la coordinación entre los Estados limítrofes en pos de la preservación y autenticidad.

Por supuesto que el mayor conflicto puede presentarse cuando alguno de estos países limítrofes reivindica la manifestación cultural como propia y exclusiva, excluyente, desconociendo o minimizando el desarrollo de aquélla en un área regional que comprende dos o más países. Asimismo, cuando dos Estados desconocen o excluyen a otro u otros países en los que aquélla puede haberse desarrollado.

Sin embargo, en el caso del Tango y Payada, el acuerdo y reconocimiento recíproco de los Estados coadyuvó a su difusión internacional y la posterior incorporación en la Lista del Patrimonio Cultural Inmaterial de la Humanidad y del MERCOSUR, respectivamente.

Aun en los casos de reconocimiento recíproco acerca del desarrollo de una manifestación cultural pueden presentarse otros conflictos en razón de distintos criterios y objetivos receptados en cada legislación nacional.

Una laguna normativa que puede generar conflictos o neutralizar la acción estatal de salvaguarda de bienes culturales, es la inexistencia o insuficiencia de régimen sancionatorio.

Por ejemplo, la legislación de un Estado sanciona toda conducta que interfiera de cualquier modo en las manifestaciones culturales; por otro lado, la legislación de otro país, autoriza a oponerse e impedir por distintos medios aquellas manifestaciones culturales que no cuenten con autorización del grupo cultural donde se originaron (ya sea agrupación de payadores o gauchos, etc). Una, tiene por finalidad la difusión de la manifestación cultural; la otra, la preservación de la identidad y respeto de los derechos de incidencia colectiva de la comunidad. De ese modo, las conductas autorizadas por la legislación de un Estado limítrofe neutralizarán las acciones del otro Estado tendientes a preservar la identidad de las prácticas culturales.

Otro conflicto puede derivar de la inexistencia de normas de protección contra el uso indebido. 
Así, por ejemplo, el artista o banda registra la autoría de música (con ritmos característicos del Tango) en el país con legislación más benigna, exhibiéndola y transmitiéndola por distintos medios para el público incluso más allá de la frontera de ese país. Ese autor podrá invocar su derecho de autor sobre esa obra musical en cualesquiera de los países del MERCOSUR (además firmantes del Convenio de Berna del 9 de septiembre de $1886^{80}$ ) sin que los miembros de las comunidades donde se originó esa práctica cultural sean compensados económicamente y sin poder defenderla de una excesiva generalización que le haga perder la identidad.

Por otro lado, la diferencia de criterios puede neutralizar las acciones de los Estados limítrofes. Así por ejemplo, en Uruguay, Argentina y Rio Grande do Sul se han fijado distintas fechas como día del payador. Estas normas jurídicas demuestran falta de coordinación. No debe perderse de vista que uno de los objetivos de la protección de los bienes culturales es su difusión y fomento, lo que exige unidad y claridad del mensaje. Esa unidad y claridad se quiebra cuando cada Estado sigue criterios distintos.

\section{Mecanismos de solución de conflictos}

Hemos descrito algunos conflictos sobre bienes culturales con respecto a los cuales pueden confluir o interferir los ordenamientos internos de los Estados limítrofes.

El medio jurídico para prevenir y/o solucionar conflictos es la celebración de convenios específicos en materia cultural. Ésta es una pauta general que imponen los arts. 27 y 99 inc. 11 de la Constitución Nacional al Estado Argentino. Especialmente, el art. 27 expresa: “El Gobierno federal está obligado a afianzar sus relaciones de paz y comercio con las potencias extranjeras por medio de tratados que estén en conformidad con los principios de derecho público...."

Por su parte, la Constitución de Uruguay prevé la solución pacífica de las diferencias (art. 6).

Es importante destacar que la República Argentina y Uruguay son signatarias de la Convención de París de $2003^{81}$ y de Berna de 1886. En virtud de la Convención de París, se comprometieron a cooperar en la protección del patrimonio cultural. Estos acuerdos específicos permitirán coordinar las medidas de preservación, restauración y difusión como así también cooperar recíprocamente evitando interferir o diluir la eficacia de las medidas administrativas adoptadas por cada uno.

A ese fin recomendamos los siguientes aspectos que deberían ser incluidos en estos acuerdos internacionales:

1-Compromiso de intercambiar datos jurídicos relevantes y actualizados (declaratorias de bienes culturales, antecedentes que las justificaron, régimen sancionatorio e información de infractores), incorporándolos en una base de datos de fácil acceso al público y gratuito.

80 Base de datos UNESCO [Disponible en: http://www.unesco.org/eri/la/convention.asp?KO=17116\&language=S\&o rder=alpha] (consultada el 28/11/2018). 
2-Acordar pautas para proteger los derechos de incidencia colectiva de los miembros de las comunidades declarados patrimonio cultural viviente (como los grupos de payadores o gauchos), tales como su derecho a la identidad, participación en la ganancias en los casos de adaptación o uso comercial de sus manifestaciones artísticas, etc.).

3-Definición de objetivos y fines específicos de la acción estatal de los Estados firmantes, ya sea antropológico e identitario, científico (preservar las fuentes materiales y objetivas de estudio), económico (particularmente, turismo).

4-Acordar conductas que deben ser sancionadas por atentar contra la integridad e identidad de las manifestaciones culturales.

5-Prever las bases jurídicas y financiamiento para investigaciones científicas binacionales o multilaterales sobre bienes culturales que se han desarrollado en un contexto regional que comprende los Estados firmantes.

Más allá de lo expuesto, estos Estados limítrofes son miembros fundadores del MERCOSUR. Por tanto, puede ser este organismo supranacional el ámbito donde puedan establecerse reglas, principios y objetivos generales a los que deba sujetarse la legislación interna de cada país, debiéndose procurar la aproximación de las legislaciones nacionales sobre patrimonio cultural, particularmente en los aspectos indicados en los párrafos precedentes.

Debemos recordar que en el MERCOSUR, las decisiones del CMC y GMC son obligatorias para los Estados miembros y deben ser incorporadas a los ordenamientos jurídicos nacionales mediante los procedimientos previstos por la legislación interna. En efecto, mediante el Tratado de Asunción firmado el 26 de marzo de 1991, los Estados miembros hicieron una delegación de competencia (autorizada por la Constitución de cada uno) creando un ordenamiento supranacional. El Tratado de Ouro Preto (arts. 9, 15, 20 y 40) dispuso que las normas emanadas de los órganos comunitarios son obligatorias para los Estados y cuando sea necesario deben ser incorporadas a los ordenamientos jurídicos nacionales mediante los procedimientos previstos por la legislación de cada país.

\section{CONCLUSIONES}

Algunos bienes culturales se han desarrollado en un contexto regional por lo que han sido declarados como patrimonio cultural por países limítrofes. Entre los objetos intangibles, el "Tango" involucra la cultura uruguaya y argentina; la "Payada" involucra a la Argentina, Uruguay, Paraguay y sur de Brasil. Estas manifestaciones intangibles se desarrollaron en el seno de grupos humanos que formaron parte del ex -Virreinato del Río de la Plata, y posteriormente, al conformar Estados independientes (Argentina, Uruguay, incluso la zona sur del Brasil anexada por ese país), pasaron a estar regidas por ordenamientos jurídicos distintos.

Estos bienes culturales regionales exigen medidas coordinadas de todos los Estados involucrados en pos de su catalogación, defensa de la autenticidad, difusión y promoción; además, presentan conflictos jurídicos cuyas soluciones deben ser previstas en las normas jurídicas. 
En general, las controversias pueden producirse por el uso indebido o desleal por terceros, la desnaturalización de la práctica cultural por factores exógenos o por el fomento desordenado y sin fines claros, o por la inexistencia de régimen sancionatorio.

En elámbito regional (Argentina y Uruguay) los conflictos internos podrían producirse por las omisiones y remisiones normativas erróneas. En especial, se producirá por la inexistencia de un registro nacional y regional de bienes nacionales, provinciales y municipales con una base de datos amplia y actualizada de acceso público que permita conocer fácilmente todas las normas jurídicas y actos administrativos emitidos en torno a cada bien cultural.

Es indispensable coordinar acciones de los Estados limítrofes donde se originó la manifestación cultural para evitar que las normas y acciones de cada uno se vean neutralizadas o interferidas por acciones o normas del otro. El medio jurídico para coordinar acciones y para prevenir y/o solucionar conflictos es la celebración de convenios específicos de coordinación.

Además, Argentina y Uruguay (también, Paraguay y Brasil) son Estados miembros del MERCOSUR. Por tanto, debe procurarse la aproximación de las legislaciones a través de los mecanismos que prevé el Tratado de Ouro Preto, particularmente, los órganos comunitarios deberían establecer reglas y objetivos generales a los que debe sujetarse la legislación interna de cada uno.

La proliferación desordenada de normas y medidas administrativas de los Estados miembros, particularmente dentro de un Estado federal, sus diferentes órbitas de gobierno (provincial y municipal) sin objetivos claros lleva a una interferencia recíproca, a la neutralización de acciones y a un desgaste innecesario e irrazonable de recursos.

En definitiva, los bienes culturales intangibles que se han desarrollado en un contexto regional exigen medidas coherentes y coordinadas de todos los Estados involucrados en su catalogación, defensa de su autenticidad y tipicidad, sensibilización, difusión y promoción, partiendo de una clara definición de objetivos y fines, estrategias y criterios.

\section{REFERENCIAS}

Castro López, M., \& Ávila Rodríguez, C. (2016). La salvaguardia del Patrimonio Cultural Inmaterial: una aproximación a la reciente Ley $N^{\circ} 10 / 2015$. Revista sobre Patrimonio Cultural: Regulación, Propiedad Intelectual e Industrial (RIIPAC), 5-6, 89-124.

Cisellia, G., Hernández, M., \& Duplattc, A. (2018). El patrimonio cultural en la normativa municipal de Comodoro Rivadavia, Argentina (1985-2016), Revista Sophia Austral, 21 (1er Semestre), 85-104.

Endere, M. L. (2007). Documento sobre la Legislación Nacional Argentina y su relación con las Convenciones establecidas por UNESCO dentro del Sector Cultura y Patrimonio Mundial. Estudio de la situación actual en Argentina, Brasil, Paraguay y Uruguay", UNESCO, 7-39. doi:http://unesdoc.unesco.org/images/0015/001599/159998s.pdf 
Endere, M. L. (2009). Algunas reflexiones acerca del patrimonio. doi: https://www.academia. edu/4174123/Algunas_reflexiones_acerca_del_patrimonio

Esaín, J. A. (2009). La distribución de competencia Nación-provincias en materia ambiental, AAVV Sabsay, Daniel (Director), Constitución de la Nación Argentina y normas complementarias (pp. 263-291). Buenos Aires: Editorial Hammurabi.

Labaca Zabala, M. L. (2013). La protección del patrimonio cultural inmaterial y la OMPI, Revista Electrónica Cartapacio de Derecho, 4. doi: http://www.cartapacio.edu.ar/ojs/ index.php/RJC/article/view/1422/0

Levrand, N. (2015). Normas de presupuestos mínimos de protección del patrimonio cultural en Argentina: ¿Posibles y vigentes? doi: http://ri.conicet.gov.ar/ bitstream/handle/11336/48957/CONICET_Digital_Nro.9aa969ce-0bfa-4a8d-9ff3c37389f96ab6_A.pdf? sequence=2\&isAllowed=y

Molina, M. (2017). La legislación argentina para la protección del patrimonio cultural sancionada en el marco del artículo 41 de la Constitución Nacional. Revista sobre patrimonio cultural: Regulación, Propiedad Intelectual e Industrial, 8, 24-60.

çMolina, M. (2018). Las limitaciones administrativas en la legislación sobre patrimonio cultural, histórico y documental, Revista La Ley Gran Cuyo, 3, 1-6.

Molina, M. (2018). Las Denominaciones de Origen protegidas simultáneamente bajo un régimen de propiedad intelectual y de patrimonio cultural intangible: un análisis en el marco del derecho argentino, Revista Iberoamericana de Viticultura, Agroindustria y Ruralidad, 5, 15, 135-156.

Villaseñor Alonso, I., \& Zolla Márquez, E. (2012). Del patrimonio cultural inmaterial o la patrimonialización de la cultura, Revista Cultura y Representaciones Sociales, 12, 75101. 